\title{
NUMERICAL ANALYSIS OF A DOUBLE SHEAR STANDARD BOLTED CONNECTION CONSIDERING MONOTONIC LOADINGS
}

\author{
Mariana Ferreira RODRIGUES ${ }^{\mathrm{a}}$, José CORREIA ${ }^{\mathrm{b}}$, Bruno PEDROSA ${ }^{\mathrm{c}}$, Abílio DE JESUS $^{\mathrm{b}}$, \\ Bruno CARVALHO ${ }^{\mathrm{d}}$, Carlos REBELO $^{c}$, José XAVIER ${ }^{\mathrm{d}}$, Rui CALÇADA ${ }^{\mathrm{b}}$ \\ anstituto de Engenharia Mecânica e Gestão Industrial, Porto, 4200-465 Portugal \\ ${ }^{b}$ Universidade do Porto, Faculdade de Engenharia, Porto, 4200-465 Portugal \\ ${ }^{c}$ Universidade de Coimbra, Departamento de Engenharia Civil, Coimbra, 3030-788 Portugal \\ ${ }^{d}$ Universidade de Trás-os-Montes e Alto Douro, Escola de Ciências e Tecnologia \\ Vila Real, 5001-801 Portugal
}

Received 09 November 2017; accepted 05 December 2017

\begin{abstract}
The behaviour of standard bolted steel connections submitted to monotonic loads, through the use of numerical models, is presented in the current paper.

The bolted connections allow speed up constructive processes in an increasingly competitive and globalized world in which the costs are a decisive factor in the development of a project. The use of computational tools in the analysis of bolted connections becomes determinant, mainly for new solutions or solutions less explored in terms of design codes.

Throughout the years, bolted connections have been suffering transformations resulting from research activities performed by many authors. Rivets have been replaced by bolts, the main achievement being the pre-stressed bolts. Methodologies based on finite element analyses were proposed for double shear bolted connection. The non-linear behaviour of these connections is investigated and their performances are compared. In the numerical modelling of the bolted connection, linear elastic and elastoplastic analyzes reveal that there are two slip levels associated with local non-linearities caused by the contact pairs, which vary with clamping stresses.
\end{abstract}

Keywords: numerical analysis, bolted connection, monotonic loadings, pre-stressed bolts.

\section{Introduction}

\section{Overview on standard bolted connections}

Nowadays, it is observed that metallic structures are increasingly used in building rehabilitation, in new constructions and in works of art (De Jesus et al. 2010). In rehabilitation, steel structures can be used at all levels, such as shoring, in order to guarantee the temporary security of the building and also as structural reinforcement (Campos 2006). In a competitive and globalized world, costs are increasingly a deciding factor in designing a project. Structural engineers are concerned with the study of bolted connections in order to develop new solutions and improve knowledge about existing solutions. It is imperative to make the most of the potential that bolted connections have shown over the years, one of which is to further accelerate the construction processes.

In general, bolted connections present various advantages when compared with other connection solutions. The main ones are (Gresnigt et al. 2012): adaptations, energy savings, use of less skilled labour, 
are a good alternative to refractories and good capacity for fatigue, especially for high- efforts. In addition, they pose less of a risk to workers, such as the risk of fire. On the other hand, the main disadvantages are: a need for greater control for the selection of net crosssections, the need for drilling of all the parts to be connected, the positioning of the holes in the plates in the manufacturing process involving sometimes a pre-assembly, preserve requirements of bolts by type and risk of torque loss when subjected to vibrations or shocks by the common bolts

\section{Applications}

The behaviour of steel bolted connections remains a problem of interest in the area of steel structures. Nowadays, it can be verified that studies on bolted connections have been growing. Researchers, all over the world, have been developing works related to bolted connections, such as: Silva (2009) carried out a numerical model according to FEM, finite element method, created in ANSYS Parametric Design Language through ANSYS 10.0 software. The mesh of the connection was composed of 3D elements of 20 nodes. Surface-to-surface contact pairs were created between the different bodies and different values for the friction coefficient were used to compare fatigue strength between riveted and bolted connections through experimental tests and numerical models. In another way, Montgomery (2008) developed a study that evaluates boundary conditions and software settings used in simulating bolts. A simulated threaded bolt with full contact is the baseline model. A model with interaction at the threaded region and one with tied contact at the threaded region is compared against the baseline model. Balc et al. (2012) elaborate an analysis with finite elements of a steel joint with end plate and prestressed bolts, using the ABAQUS finite element software code. Relatively to injected bolts, Kortiš (2011) carried out a numerical model of a riveted connection. Three different numerical models of shear connections were created: one approach was implementing two rivets, the other was using one injected bolt and one rivet and the other was using one low-quality injected bolt together with one rivet. The effective stress on the rivet was compared for these three models. Correia et al. (2017) presents a comparison between two alternative finite element models proposed to predict the fatigue strength of a single shear and single rivet connection.
The first model is based on solid finite elements as well as on contact elements, to simulate contact between the components of the connection. The second model is built using shell finite elements in order to model the plates of the riveted connection.

According to Kwon et al. (2002), to predict the accurate behaviour of bolted joints, detailed 3D modelling needs to consider the contact, the preload, and nonlinear behaviour of joints. However, a detailed model with gap elements cannot ensure convergence due to the complicated shape, besides being unsuitable for a dynamic analysis. Yorgun et al. (2004) modelled a finite element to evaluate the behaviour of a double channel beam-to-column connection subjected to, in plane, bending moment and shear. Simulation of the tests was carried out by means of a nonlinear finite element software ANSYS. In the study carried out by Maggi et al. (2005) are presented the results of parametric analyses on the behaviour of bolted extended end plate connections using Finite Element (FE) modelling tools. The analytical models took into account material nonlinearities, geometrical discontinuities and large displacements. In the model proposed by Zhang (Zhang, Poirier 2004), the member deformation is determined by the member stiffness that remains unchanged whether the external load is present.

Lazzarin (Lazzarin, Quaresimin 1995) carried out a statistical analysis performed on ca 750 fatigue data reported in the literature. All data can be used for establishing trends, planning future research and for design purposes. Berto et al. (2016) carried out a comparison between hot dip galvanized fillet welded cruciform joints made by S355, structural steel and not treated welded joints characterized by the same geometry, subjected to a load cycle $\mathrm{R}=0.34$.

\section{Numerical modelling of double shear bolted connection under monotonic loading}

\subsection{Geometry of the connection and used materials}

The geometry of the double shear bolted connection was configured the dimensions shown in Figure 1 and 2. The connection consists of two plates connected with an M22×70 bolt and a 3mm thick washer. Table 1 summarizes the materials and elastic properties considered in the simulation of double-shear bolted connection. 


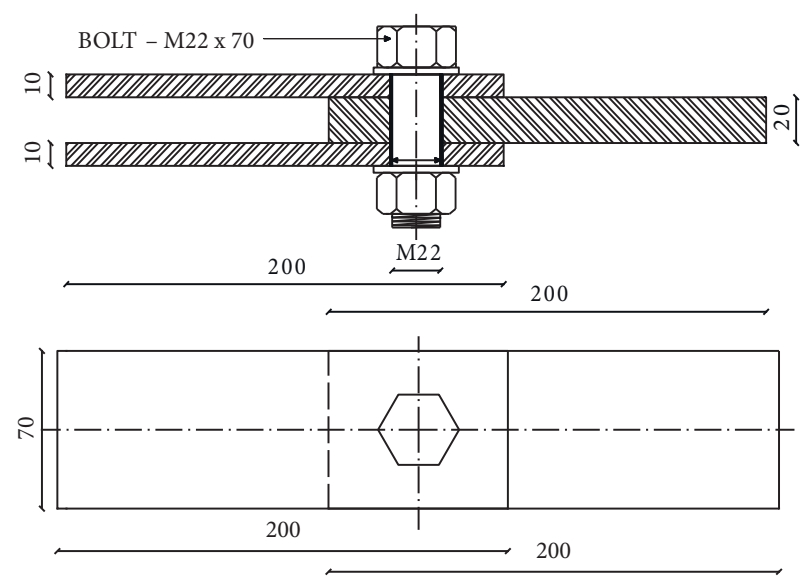

Fig. 1. Bolted connection geometry (dimensions in $\mathrm{mm}$ )

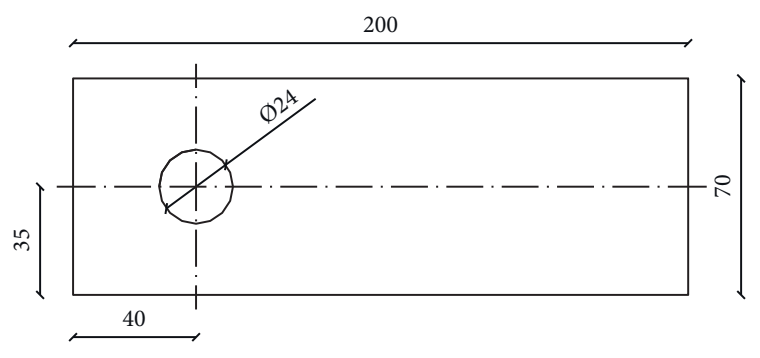

Fig. 2. Geometry of $10 \mathrm{~mm}$ and $20 \mathrm{~mm}$ plates (dimensions in $\mathrm{mm}$ )

Table 1. Materials and elastic properties used in double shear connection.

\begin{tabular}{|c|c|c|c|c|}
\hline Description of the body & ANSYS designation & Material & Poison Ratio $(v)$ & Elasticity Modulus (E) [GPa] \\
\hline Plate $10 \mathrm{~mm}$ & Body 1 & S355 & 0.30 & 210 \\
\hline Plate $20 \mathrm{~mm}$ & Body 2 & S355 & 0.30 & 210 \\
\hline Bolt M22 $\times 70+$ washer & Body 3 & Class 8.8 & 0.30 & 210 \\
\hline
\end{tabular}

\subsection{Finite element modelling}

The bolted connection was modelled with a $3 \mathrm{D}$ mesh composed by solid 20 quadrilateral elements (SOLID186). Three bodies were created: 1 and 2, shown in Figure 3 and 3 (bolt + washer) shown in Figure 4.

Since the material of the plates in the proximity of the holes will be subjected to a higher concentration and gradient of stresses, a refinement of the finite element mesh was carried out at this location.

Since the double shear bolted connection has two planes of symmetry, only a quarter of the connection was modelled, in order to reduce the computational cost of the simulations. This step was possible by the imposition of null displacements in the direction perpendicular to the planes of symmetry ( $Y$ and $Z$ axes).
Contact pairs were created to simulate the contact interactions between the various bodies. Before modelling the contact problem, it is necessary to identify the potential interactions between the various bodies. Figure 5 shows the four steel / steel contact pairs created, which were:

- Contact between body 1 (10mm plate) and body 2 (20mm plate): 1 st contact pair;

- Contact between body 3 (bolt head plus washer) and body 1 (10mm plate) - 2nd contact pair;

- Contact between body 1 (10mm plate) and body 3 (bolt tang): 3rd contact pair;

- Contact between body 2 (20mm plate) and body 3 (bolt shank): 4 th contact pair;

The contact was modelled using the contact element technology available in the ANSYS software, us-

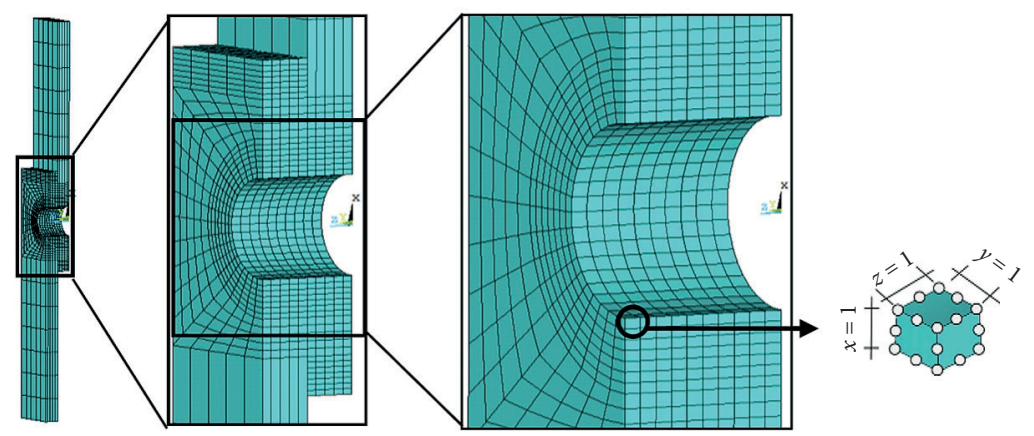

Fig. 3. Discretization of body 1 (lateral plate) and body 2 (central plate) and detail of the finite element formed by 20 nodes 
ing surface-to-surface contact options and assuming flexible-flexible contact between surfaces (ANSYS ${ }^{\circledR} 12.0$ code: SAS 2011). First the surfaces between the different bodies that could potentially come into contact were selected and then 8-node elements (TARGE170 and CONTA174) were generated on these surfaces to respectively model all the contact pairs between the same bodies. Figure 6 shows the final appearance of the double shear connection.

\subsection{Parameters of the numerical models}

Montgomery (2008) refers that bolted connections present various complexities in finite element modelling and are impractical in current simulations. He also points out that other authors also highlight these complexities associated with bolted joints. a) 3D Perspective

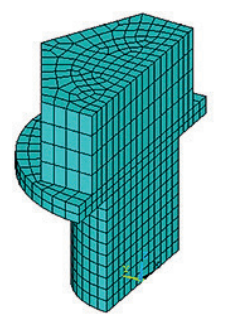

c) Back view

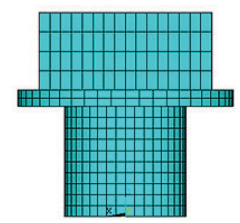

b) Top view

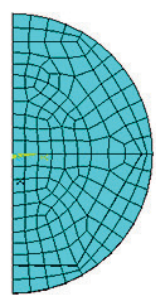

d) Front view

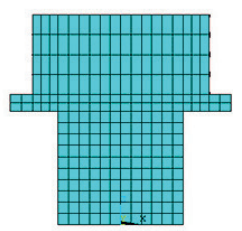

Fig. 4. Discretization of body 3 (bolt M22×70 + washer) using solid finite elements of 20 nodes

a) $1^{\text {st }}$ pair of contact

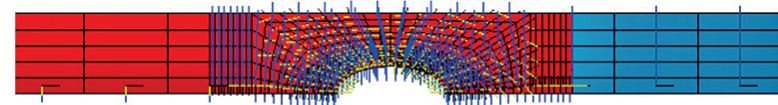

b) $2^{\text {nd }}$ pair of contact

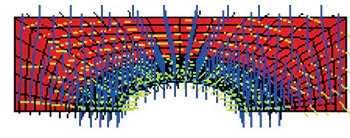

c) $3^{\text {rd }}$ and $4^{\text {th }}$ pair of contact
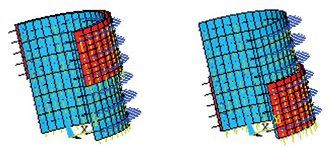

Fig. 5. Contact pairs created in ANSYS software

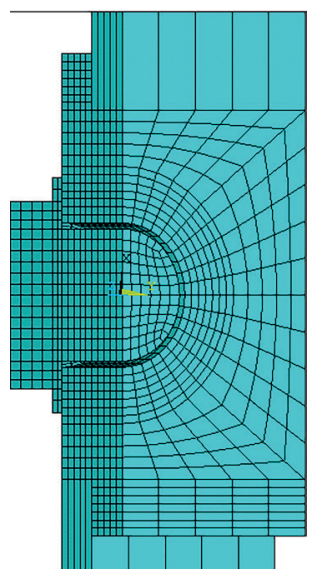

Fig. 6. Local finite element mesh

Simulations were performed using the Lagrange contact algorithm. This requires the definition of the normal contact stiffness and the interpenetration tolerance of the contact pairs to be applied in the normal direction to the contact surface. The contact stiffness is estimated by the ANSYS based on the elastic properties of the bodies in contact and can be affected by a multiplicative factor, defined as the parameter FKN. The penetration tolerance is defined by the FTOLN parameter and is also a multiplicative factor to be applied to the thickness of the first layer of solid elements of the bodies in contact. According to Silva (2009), the amount of penetration between the contact surfaces depends on the value of the normal contact stiffness. For high stiffness values there is a reduction in penetration, increasing the convergence difficulties of the contact algorithm. Reduced values of the contact stiffness can lead to high penetrations, thus producing less precise solutions. In this way, a sufficiently high stiffness is intended to reduce interpenetration between bodies to acceptable values, ensuring convergence to the solution in a timely manner. According to the study carried out by Silva (2009), the optimal values for these parameters are as follows:

- FKN (contact stiffness factor) equal to 0.1 ;

- FTOLN (penetration tolerance factor) equal to 0.1 .

These values were applied in the present study. For the remaining parameters related to the Lagrange contact algorithm, which were not explicitly mentioned, the values suggested by default were adopted by the ANSYS commercial code.

Another parameter that has an influence on the behaviour of the connections is the gap between the bolt and the holes in the plates. The gap is defined as 
the difference between the diameter of the bolt and the diameter of the holes. In numerical models, the clearance value assumed was $2 \mathrm{~mm}$. In all numerical models of the double-shear bolted connection, the diameter of the bolts is constant and equal to $22 \mathrm{~mm}$.

The materials presented in Tables 1 were modelled with elastoplastic behaviour. It was adopted the criterion yielding von Mises, with isotropic hardening defined by a multilinear law. For the S355 steel the uniaxial stress-strain curve was adopted according to Figure 7.

For the bolts, a uniaxial stress-strain curve was used, shown in Figure 8. Class 8.8 bolts were adopted, with a tensile strength of $800 \mathrm{MPa}$ and yield strength of $640 \mathrm{MPa}$.

In this study, the Coulomb friction model was adopted. The friction coefficient required in this model was estimated based on the recommendations of EC3 standard the coefficients vary between 0.2 and 0.5 depending on a diversity of factors in which the roughness of the surfaces in contact is one of the most determinant. In this case, two different friction coefficient,

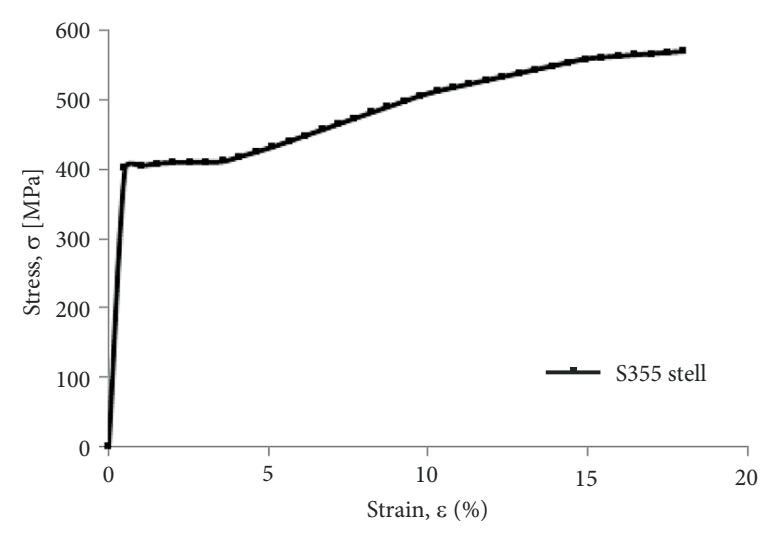

Fig. 7. Uniaxial stress-strain behaviour of S355 steel

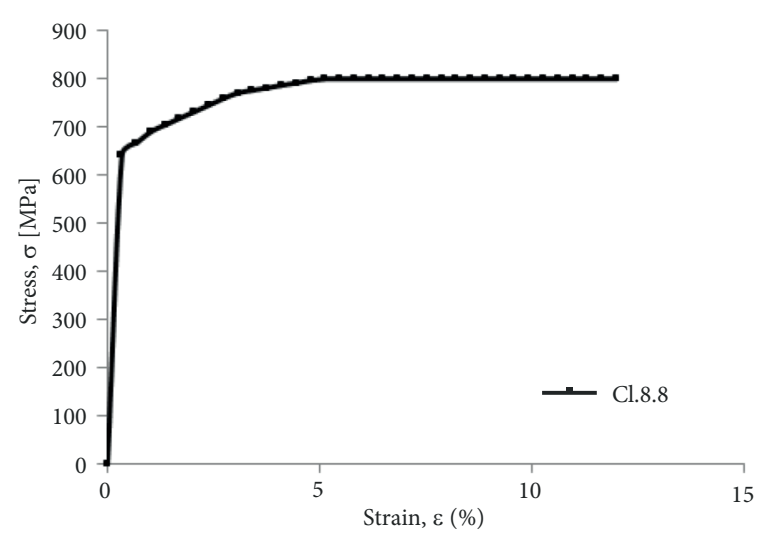

Fig. 8. Uniaxial stress-strain behaviour adopted for materials used in M22 bolts of resistance class 8.8 $\mu=0.2$ and 0.5 , were taken into account. On the other hand, in order to perceive and evaluate the influence of the friction coefficients on the connection, it was considered in some cases, all the discrete values mentioned in the codes (Cruz et al. 2012; EN 1090-2 2011).

According to Montgomery (2008) and Kim et al. (2006), clamping stresses in bolted connections can be modelled by one of the following processes: thermal deformation, with constraint equations or by imposing initial deformations.

According to the thermal deformation method, pre-stressing is generated by assigning virtual temperature variations and orthotropic thermal expansion coefficients to the bolt body (Montgomery 2008; Kim et al. 2006). In the case of the constraint equations, these are formulated for the relevant bolt body nodes (Montgomery 2008; Kim et al. 2006). The initial deformation method is the most direct approach, where the initial displacement is imposed on the bolt body (Montgomery 2008; Kim et al. 2006).

For the current study, the clamping stress in the connection was created through the application of a temperature range, $\Delta T$. By applying a temperature reduction on the bolt, it is possible to induce the contraction of the bolt producing a compression force at the connection. For this purpose, it was considered that the material of the bolt body has orthotropic thermal expansion properties, particularly the thermal expansion coefficient is zero in the transverse directions $\left(\alpha_{x}=\alpha_{y}=0\right)$ and $\alpha_{z}=1.0 \times 10-5 /{ }^{\circ} \mathrm{C}$ in the longitudinal direction of the bolt.

Using the numerical model of the double shear connection and standard bolts and assuming elastic behaviour of the materials, the reference temperatures, $T_{\text {ref }} 0{ }^{\circ} \mathrm{C}, 100{ }^{\circ} \mathrm{C}, 475^{\circ} \mathrm{C}, 500{ }^{\circ} \mathrm{C}, 700{ }^{\circ} \mathrm{C}$ and $900{ }^{\circ} \mathrm{C}$ were tested in order to calibrate of the clamping stress equations, $\sigma_{p e}$, as a function of the temperature range, for the friction coefficient, of 0.2 and 0.5 . These calibration equations will allow to estimate the temperature ranges to be applied to the bolts in order to result in a certain clamping stress.

For the simulation of the clamping stress, the temperature variation is defined by the difference between the reference temperature, $T_{r e f}$ and the ambient temperature, $T_{a m b}$, according to the following equation:

$$
\Delta T=T_{r e f}-T_{a m b}
$$

An ambient temperature of $25^{\circ} \mathrm{C}$ was considered. 
In order to study the effect of the clamping stress variation on the bolts in the behaviour of the doubleshear connection, the following clamping stress values were simulated in the three numerical models: $50 \%$, $60 \%, 70 \%, 80 \%$ and $90 \%$ of the ultimate strength of the M22 class 8.8 bolts.

The displacement imposed parameter is very important, since the extension of non-linear behaviour will depend on the maximum imposed value. The values adopted for these displacements were $0.10 \mathrm{~mm}$, $1.0 \mathrm{~mm}$ and $10 \mathrm{~mm}$. The imposed displacements were defined in the longitudinal axis $x$ (loading direction). These displacements were applied to the nodes that constitute the volume of the tie of the body 1 and in the opposite direction was adopted null displacement in the volume of the grip of the body 2. In some simulations the displacement up to $13 \mathrm{~mm}$ was extended to show the last load of the connection.

Table 2 presents the Modelling parameters used in the numerical analysis of the bolted connection.

\section{Results and discussion}

The first simulations were carried out to determining the relation between the clamping stress and the temperature range applied to the bolt body.

Figure 9 shows the evolution of clamping stress for the temperature range of $0{ }^{\circ} \mathrm{C}, 100^{\circ} \mathrm{C}, 475^{\circ} \mathrm{C}, 500^{\circ} \mathrm{C}$, $700{ }^{\circ} \mathrm{C}$ and $900{ }^{\circ} \mathrm{C}$ and for the friction coefficients, 0.2 and 0.5 . These simulations were carried out in a linearelastic regime for double-shear connection. It was verified that the values of the clamping stress that translate the tightening of the connection to the friction coefficients of 0.2 and 0.5 , are practically coincident. It is also verified that the temperature range and clamping stress are linearly related. The higher the temperature range, the higher the clamping stress on the bolts.

Table 3 lists several clamping stress values used in this study and their required temperature range. This values correspond to percentages of the ultimate tensile strength of the 8.8 bolts, namely $50 \%, 60 \%, 70 \%$, $80 \%$ and $90 \%$.

\subsection{Linear-elastic numerical analysis}

The stress fields in the connection were obtained in the elastic regime. These stress fields allow to locate the critical point of the connection to determine the linear-elastic stress concentration factor, $K_{t}$. As was expected, the maximum stress values were obtained near the holes in the plates.
Table 2. Modelling parameters used in the numerical analysis of the bolted connection

\begin{tabular}{|c|c|c|c|c|}
\hline $\begin{array}{c}\text { Numerical } \\
\text { analysis }\end{array}$ & FKN & FTOLN & $\begin{array}{c}\text { Friction } \\
\text { coefficient, } \mu\end{array}$ & $\begin{array}{l}\text { Clamping } \\
\text { stress, } \sigma_{p e}\end{array}$ \\
\hline \multirow{10}{*}{ Linear-elastic } & \multirow{10}{*}{0.1} & \multirow{10}{*}{0.1} & \multirow{5}{*}{0.2} & 400 \\
\hline & & & & 480 \\
\hline & & & & 560 \\
\hline & & & & 640 \\
\hline & & & & 720 \\
\hline & & & \multirow{5}{*}{0.5} & 400 \\
\hline & & & & 480 \\
\hline & & & & 560 \\
\hline & & & & 640 \\
\hline & & & & 720 \\
\hline \multirow{20}{*}{ Elastoplastic } & \multirow{20}{*}{0.1} & \multirow{20}{*}{0.1} & \multirow{5}{*}{0.2} & 400 \\
\hline & & & & 480 \\
\hline & & & & 560 \\
\hline & & & & 640 \\
\hline & & & & 720 \\
\hline & & & \multirow{5}{*}{0.3} & 400 \\
\hline & & & & 480 \\
\hline & & & & 560 \\
\hline & & & & 640 \\
\hline & & & & 720 \\
\hline & & & \multirow{5}{*}{0.4} & 400 \\
\hline & & & & 480 \\
\hline & & & & 560 \\
\hline & & & & 640 \\
\hline & & & & 720 \\
\hline & & & \multirow{5}{*}{0.5} & 400 \\
\hline & & & & 480 \\
\hline & & & & 560 \\
\hline & & & & 640 \\
\hline & & & & 720 \\
\hline
\end{tabular}

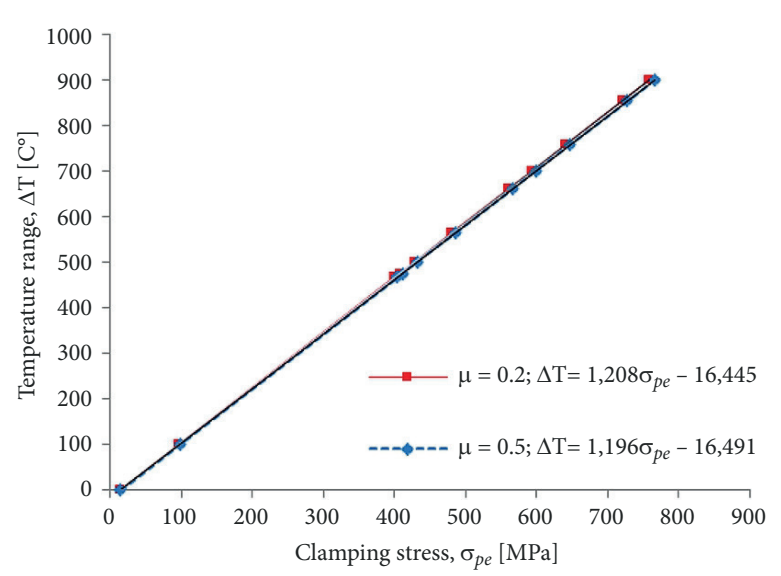

Fig. 9. Relation between the clamping stress, $\sigma_{p e}$, and the temperature range, $\Delta T$, applied to the bolt body 
Table 3. Selected values of clamping stresses

\begin{tabular}{|c|c|c|c|c|c|}
\hline \multirow{2}{*}{$\sigma_{p e}(\mathrm{MPa})$} & \multirow{2}{*}{$\frac{\sigma_{p e}}{R m}(\%)$} & \multicolumn{2}{|c|}{$\Delta T\left({ }^{\circ} \mathrm{C}\right)$} & \multirow{2}{*}{$\Delta T(\mu 0.2-\mu 0.5)\left({ }^{\circ} \mathrm{C}\right)$} & \multirow{2}{*}{$\Delta T(\%)$} \\
\hline & & $\mu=0.2$ & $\mu=0.5$ & & \\
\hline 720 & $90 \%$ & 853.32 & 844.63 & 8.69 & $1.02 \%$ \\
\hline 640 & $80 \%$ & 756.68 & 748.95 & 7.73 & $1.02 \%$ \\
\hline 560 & $70 \%$ & 660.04 & 653.27 & 6.77 & $1.03 \%$ \\
\hline 480 & $60 \%$ & 563.40 & 557.59 & 5.81 & $1.03 \%$ \\
\hline 400 & $50 \%$ & 466.76 & 461.91 & 4.85 & $1.04 \%$ \\
\hline
\end{tabular}

Using the stress distributions obtained through the MEF, the stress concentration factor was determined in the elastic regime. The analysis of the evolution of the stress concentration factor allowed the analysis of several parameters that influence the behaviour of the connection.

The linear-elastic stress concentration factor was defined as the ratio between the maximum local stress in the load direction and the nominal stress:

$$
K_{t}=\frac{\sigma_{\max }}{\sigma_{\text {nom }}}=\frac{\sigma_{\max }}{\frac{F}{A_{\text {net }}}},
$$

where: $\sigma_{\max }$ is the maximum local stress in the load direction; $\sigma_{\text {nom }}$ is the nominal stress determined in the section containing the bolt axis; $F$ is the force applied at the connection;

$A_{\text {net }}$ is the connection resistant area by discounting the bolt hole.

In Figures 10 and 11, the evolution of the linearelastic stress concentration factor for body 1 and 2 (lateral and central plate, respectively) is shown, as a function of the clamping stress, friction coefficient and imposed displacements.

The structural behaviour of the connection in elastic regime is presented below through the respective force versus displacement curves, for the various friction coefficients and clamping stress values applied.

According to Figures 12 and 13, the clamping stress retards sliding between the connecting plates. For a displacement equal to $10 \mathrm{~mm}$, the force applied in the loading direction increases with the clamping stress installed. From Figure 13, it is verified for this numerical model of connection the existence of two slip phases, for all the clamping stresses. The first slip occurred due to the existence of the gap $(2 \mathrm{~mm})$ between the bolt body and the holes in the plates. In the first slip, the body 2 (central plate) abuts the body 3 (bolt), in the second slip phase, the body 1 (lateral

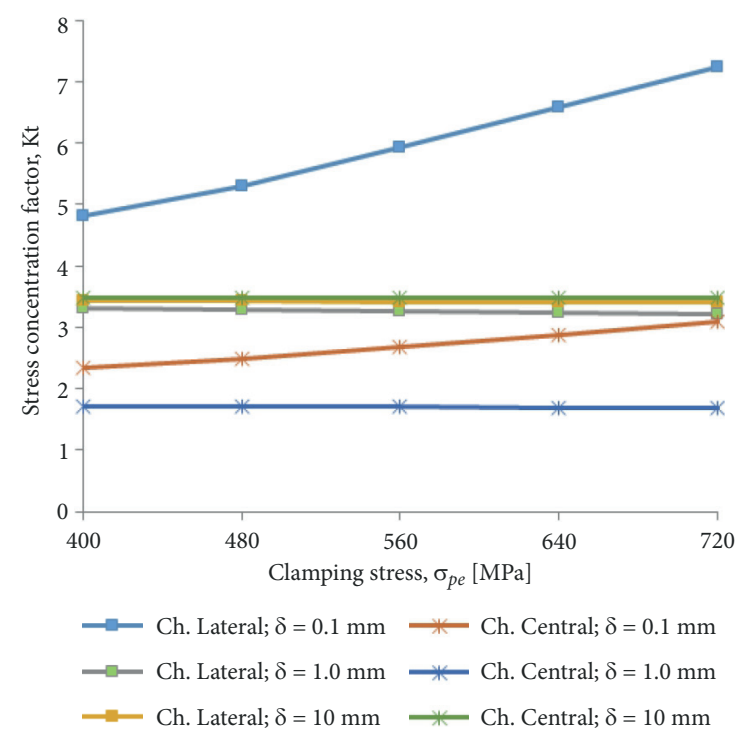

Fig. 10. Evolution of linear-elastic stress concentration factor, $\mu=0.2$

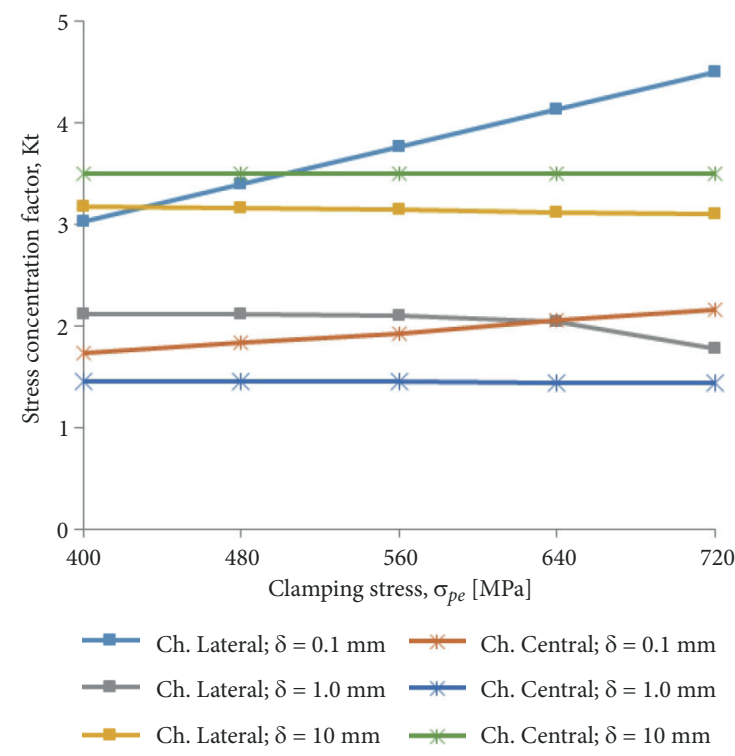

Fig. 11. Evolution of linear-elastic stress concentration factor, $\mu=0.5$

plate) abuts the bolts. After the total sliding of the plates, the various clamping stress curves converge with each other. 


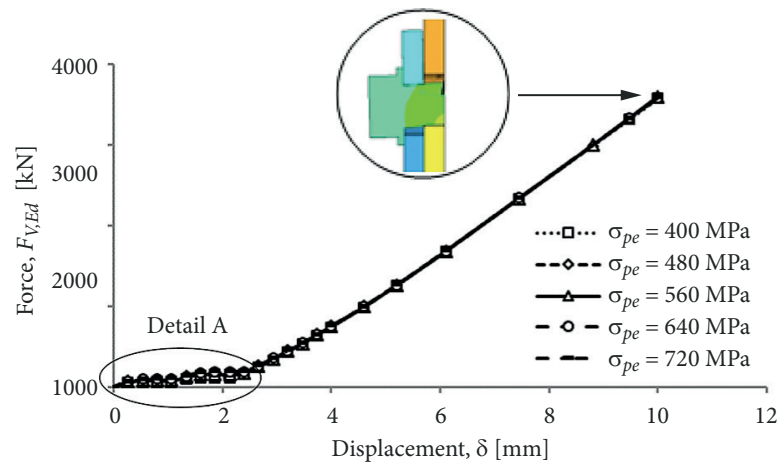

Fig. 12. Connection behaviour in elastic regime, for displacement up to $10 \mathrm{~mm}$, friction coefficient equal to 0.2 and varying the clamping stresses

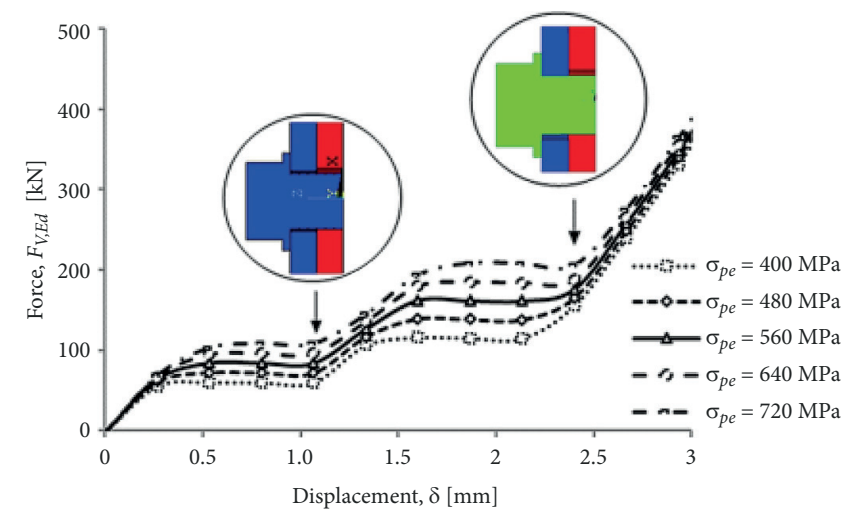

Fig. 13. Detail A of the behaviour of the connection in elastic regime for displacement up to $10 \mathrm{~mm}$, friction coefficient equal to 0.2 and varying the clamping stresses

For displacement equal to $1 \mathrm{~mm}$ only the first slip phase occurred in which the body 2 (central plate) pressed against the body 3 (bolt). The loading force increased with the clamping stress. The force applied in the loading direction increased with the clamping stress installed in the slip zone and immediately after that.

For the value of friction coefficient equal to 0.5 , the observed behaviour of the connection in elastic regime is the one realized for a friction coefficient of 0.2 . From the analysis of Figures 14 and 15, it is verified that the connection presents two slip phases, after which the curves tended to converge, meaning that its structural behaviour is no longer influenced by this parameter in a significant way.

For a displacement equal to $1 \mathrm{~mm}$ only a partial slip occurred, in which the body 2 (central plate) pressed against the body 3 (bolt). The force applied in the loading direction increased with the clamping stress installed in the slip zone and immediately after that.

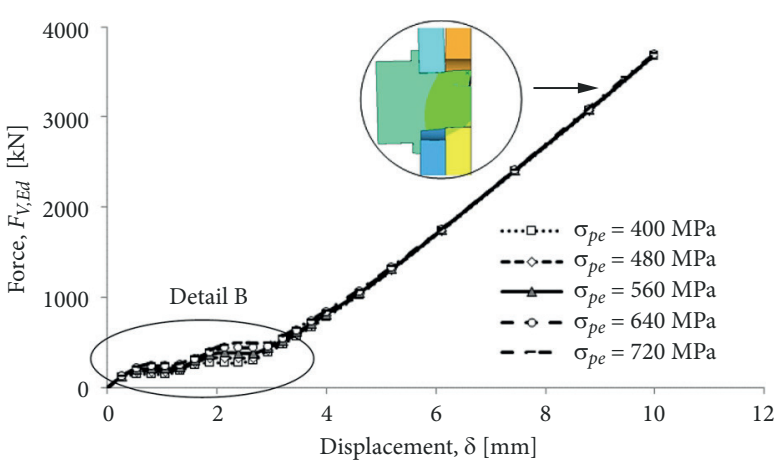

Fig. 14. Connection behaviour in elastic regime, for displacement up to $10 \mathrm{~mm}$, friction coefficient equal to 0.5 and varying the clamping stresses

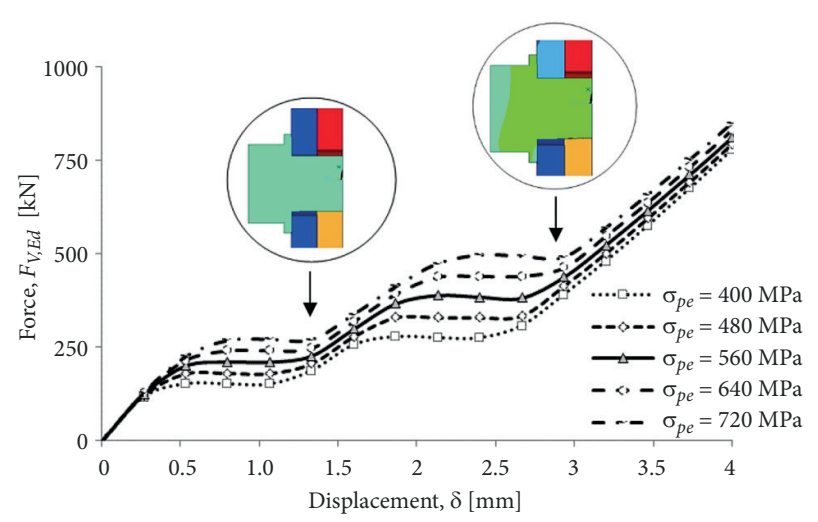

Fig. 15. Detail B of the behaviour of the connection in elastic regime for displacement up to $10 \mathrm{~mm}$, friction coefficient equal to 0.5 and varying the clamping stresses

\subsection{Elastoplastic numerical analysis}

The modelling of the connection behaviour assuming elastic behaviour of the materials does not allow to obtain an estimate of the connection breaking loads. Thus, this behaviour is presented as a function of the installed clamping stress and friction coefficient.

Figure 16 shows the load-displacement curve for a coefficient of friction equal to 0.2 for several clamping stress values. For all clamping stress values, there were two slip phases in the connection. It was found that immediately after the second slip, the values of bond strength loads converge independently of the applied clamping stress values.

The load-displacement results for a friction value of 0.5 are shown in Figure 17. For all simulated clamping stresses, two slip phases were also observed at the connection. Initially, the connection exhibited a linear behaviour until the first slip occurred, where the body 2 abutted the body 3 . After this slip, the force applied in the loading direction has increased again until there is again a second slip, in which the body 1 touched 


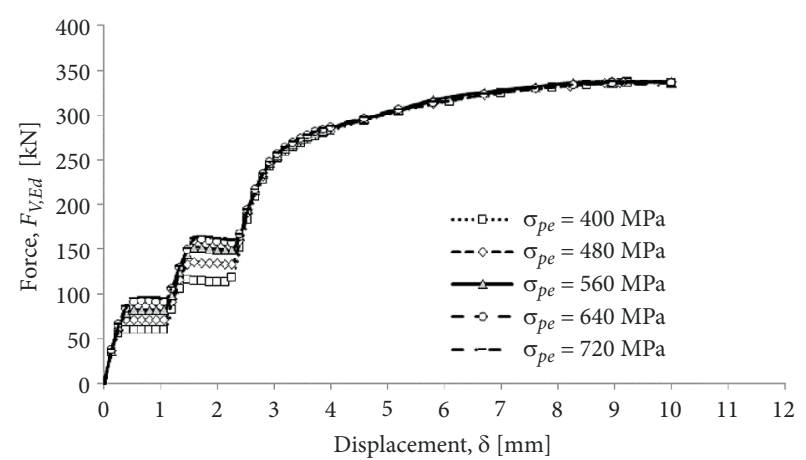

Fig. 16. Connection behaviour in elastoplastic regime, for displacement up to $10 \mathrm{~mm}$, friction coefficient equal to 0.2 and varying the clamping stresses

the body 3. At the end of the total slipping of the connection, the resistance increased slightly as a function of the clamping stress until it began to plasticize and reach the collapse load.

In the behaviour of the connection up to the displacement of $3 \mathrm{~mm}$, it is verified that the clamping stress has a significant influence in the delay of the slips. After this displacement, the values of the clamping stress lose relevance, since the curves F- $\delta$ converge with each other.

In summary, it was found that the friction coefficient and clamping stress significantly influence the slipping retardation of the plates. The higher their values, the greater the resistance of the slipping connection and the closer the slipping resistance of the last loads of the connection.

In order to confirm the ultimate tensile strength of the connection, for the same friction coefficients and clamping stress values, the maximum displacement up to $13 \mathrm{~mm}$ was increased. The results obtained are shown in Figure 18.

In the analysis of Figures 18 and 19, it was found that the connection with friction coefficient equal to 0.2 and 0.5 maintained the same behaviour when compared with the previous results obtained for a displacement up to $10 \mathrm{~mm}$. The ultimate loads for the various clamping stress were very close to each other.

In Figure 18, for the friction value equal to 0.2 , it was verified that the load-displacement curves converged between the displacements between 2 and 3 $\mathrm{mm}$, for any clamping stress value. In Figure 19, for the friction value equal to 0.5 , this convergence happened later and for the displacement range between 4 and $5 \mathrm{~mm}$. It is also confirmed that the friction coefficient had a significant influence on the structural behaviour of the connection, causing slip between the plates.

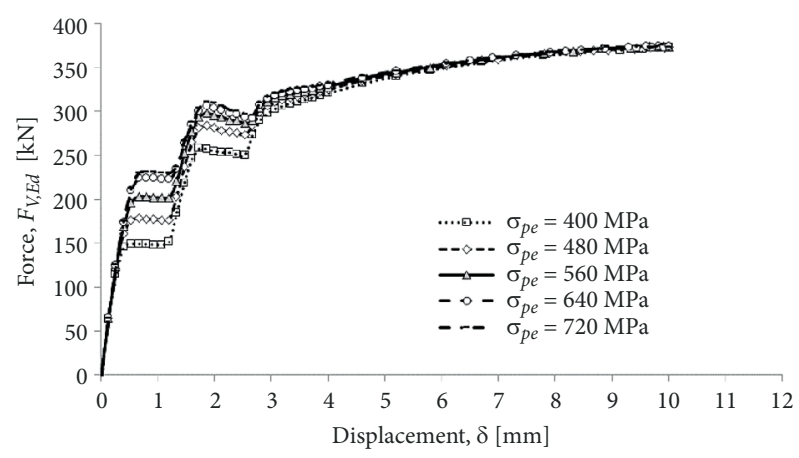

Fig. 17. Connection behaviour in elastoplastic regime, for displacement up to $10 \mathrm{~mm}$, friction coefficient equal to 0.5 and varying the clamping stresses

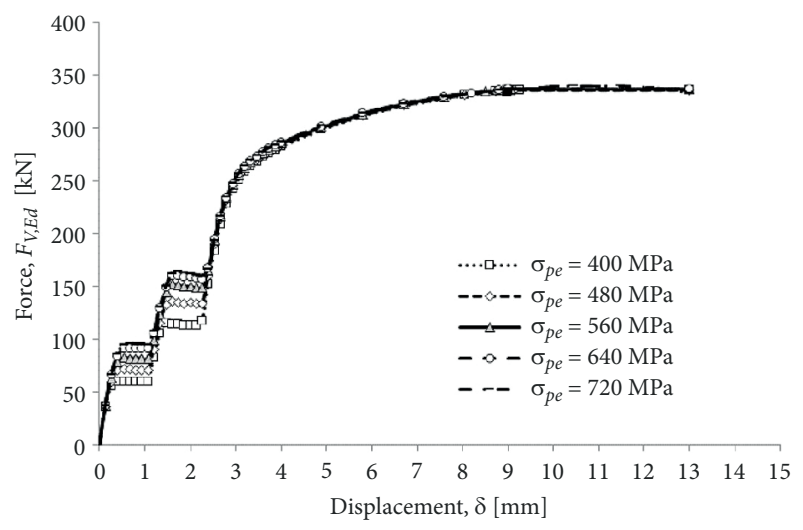

Fig. 18. Connection behaviour in elastoplastic regime, for displacement up to $13 \mathrm{~mm}$, friction coefficient equal to 0.2 and varying the clamping stresses

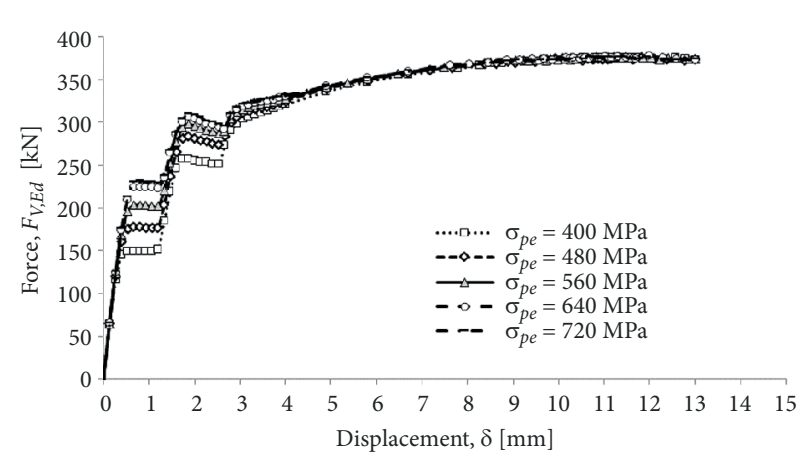

Fig. 19. Connection behaviour in elastoplastic regime, for displacement up to $13 \mathrm{~mm}$, friction coefficient equal to 0.5 and varying the clamping stresses

With respect to the clamping stress effect, it is also observed in Figures 18 and 19 that the higher this stress, the greater the forces applied in the connection to cause slipping of the plates. After the second slip, the load-displacement curves tend to converge between them, meaning that the structural behaviour of the connection is no longer significantly influenced by this parameter. It was verified that the greater influence of the clamping stress occurs in the levels of slipping. 
a) $\mu=0.2$

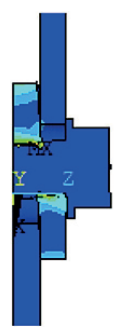

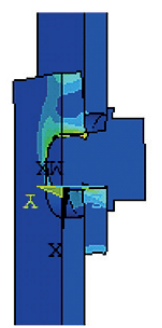
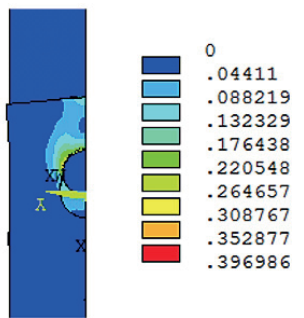

b) $\mu=0.5$
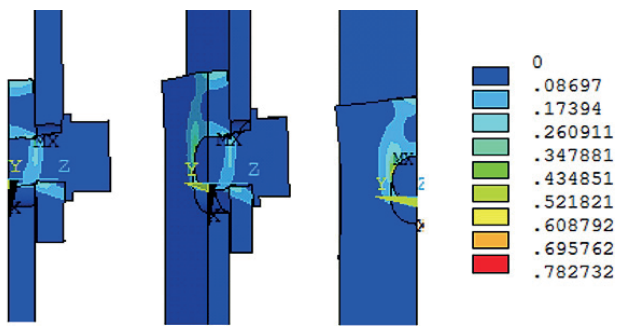

Fig. 20. Distribution of the equivalent plastic deformations according to Von Mises criteria $\left(\sigma_{p e}=560 \mathrm{MPa}, \delta=13 \mathrm{~mm}\right)$

The analysis of the possible breaking modes was performed using a numerical model with the following parameters: $\sigma_{p e}=560 \mathrm{MPa}, \delta=13 \mathrm{~mm}$ and the coefficients of friction equal to 0.2 and 0.5 . According to Figure 20 and evaluating the distribution of the plastic deformations in the bodies, there are two possible rupture modes. It can be concluded that there may be a plastic crack in the central plate as well as a plastic crack in the bolt. In both cases these are modes of cracking by shear force. For the selected dimensions of the connection, the tensile crack in the resistant section is not feasible. The maximum plastic deformations observed are very significant, above the typical breaking strength of the steels. It should be noted, however, that the deformations obtained through the MEF are logarithmic deformations, whereas the values of the rupture extension usually referenced in the literature correspond to engineering values. The analysis of Figure 20 shows a great influence of the coefficient of friction in the field of equivalent plastic deformations.

In order to understand the influence of the friction coefficient on the connection behaviour, the results of simulations carried out with a friction coef-

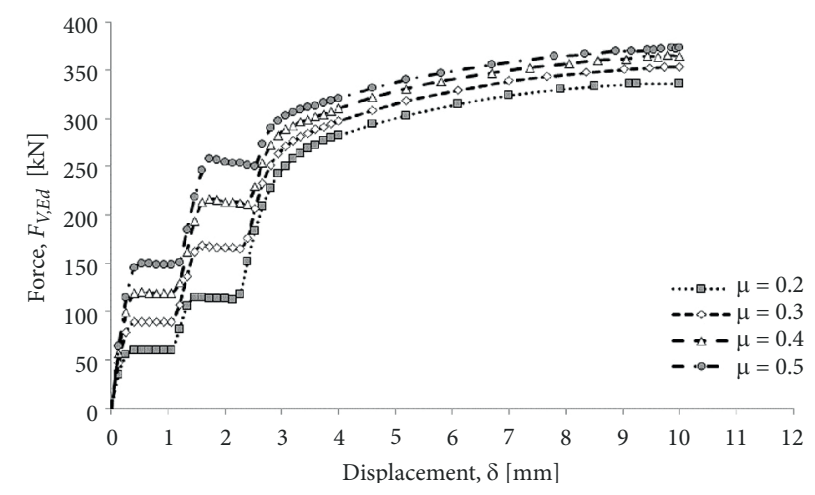

Fig. 21. Structural behaviour of the double-shear connection for a displacement up to $10 \mathrm{~mm}$ and a clamping stress of $400 \mathrm{MPa}$, depending on the various friction coefficients ficient of 0.2, 0.3, 0.4 and 0.5 were compared for some clamping stress values and imposing equal maximum displacements to $10 \mathrm{~mm}$. The assumed values for the clamping stress were 400, 560 and $720 \mathrm{MPa}$. The results are shown in Figures 21, 22 and 23.

The analysis of Figures 21, 22 and 23 for all friction coefficient reveals that the connection initially exhibits elastic behaviour until the occurrence of the first slip. In the same way as mentioned above, in the first slipping level the resistant force decreases significantly with the reduction of the friction coefficient. After this

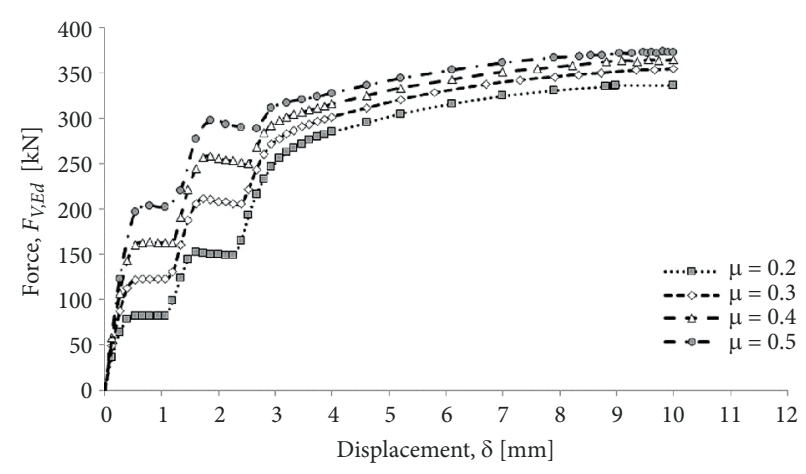

Fig. 22. Structural behaviour of the double-shear connection for a displacement up to $10 \mathrm{~mm}$ and a clamping stress of $560 \mathrm{MPa}$, depending on the various friction coefficients

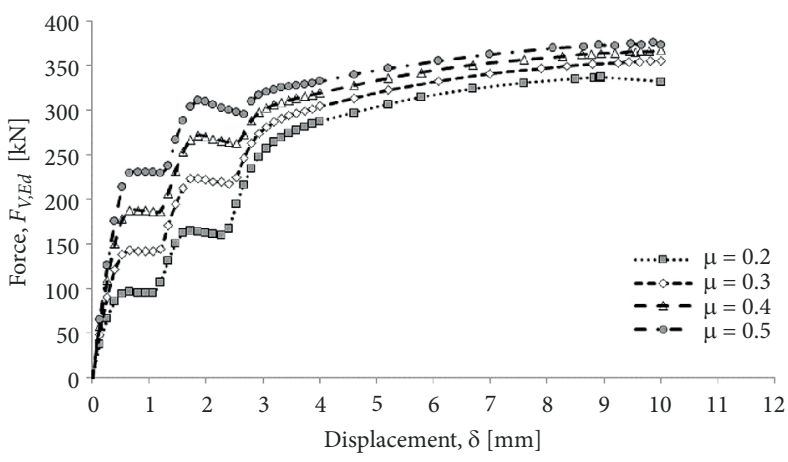

Fig. 23. Structural behaviour of the double-shear connection for a displacement up to $10 \mathrm{~mm}$ and a clamping stress of $720 \mathrm{MPa}$, depending on the various friction coefficients 
first slip in which the body 2 contacts the body 3 , the force again increases again until a second slip occurs. At that instant, the body 1 contacts the body 3 . Subsequent to this last slip, the force increases again until the connection reaches the level of plasticity and consequent failure.

\section{Conclusions}

The main conclusions regarding the finite element modelling of this type of steel connection is that the definition of the appropriate constitutive model for the materials is the most important step of the modelling process since it must be based on experimental information and depends on the quality of the results obtained. The modelling requires a careful analysis on the location where the possible critical points that are susceptible to larger peaks and strain / strain gradients will exist. At these points the mesh must have an adequate density. It is necessary to keep in mind that local stresses and deformations fields are nonlinear due to the contact between the connection elements (Carvalho 2013).

Through the results obtained from the numerical simulations it can be concluded that the higher the temperature range the higher the clamping stress installed on the connection bolts. Still through the elastic analysis, it is concluded that the relation between the clamping stress and the temperature range is practically insensitive to the variation of the friction coefficient.

In the simulated conditions, the critical point is always located near the holes of the plates and the higher the friction coefficient and clamping stress, the higher the bond strength to failure when subjected to monotonic loads. In addition, there are always two slip levels between the plates and with slipping resistance loads dependent on clamping stress and friction coefficient. After total imposed slip, all resistance vs. displacement curves tend to converge between them (Carvalho 2013).

\section{Acknowledgements}

The authors acknowledge the Portuguese Science Foundation (FCT) for the financial support through the doctoral and post-doctoral grants, SFRH/BD/135257/2017 and SFRH/BPD/107825/2015, respectively. Authors gratefully acknowledge the funding of SciTech - Science and Technology for Competitive and Sustainable Industries (NORTE-01-0145-FEDER-000022),
R\&D project cofinanced by Programa Operacional Regional do Norte ("NORTE2020"), through Fundo Europeu de Desenvolvimento Regional (FEDER).

\section{References}

Balc, R.; Chira, A.; Chira, N. 2012. Finite element analysis of beam to column end plate bolted connection, Acta Technica Napocensis: Civil Engineering \& Architecture 55(1): 24-29.

Berto, F.; Mutignani, F.; Tisalvi, M.; Laurenti, A. 2016. Effect of hot-dip galvanization on the fatigue behavior of notched and welded structural Steel, Ingegneria Ferroviaria 2: 105-118.

Campos, L. 2006. Técnicas de Recuperação e Reforço Estrutural com Estruturas de Aço: MSc. Thesis. Federal University of Rio de Janeiro, Brasil (in Portuguese). 104 p.

Carvalho, B. 2013. Modelação por Elementos Finitos do Comportamento de Ligações Aparafusadas Sem e Com Resina Injectada: MSc. Thesis. University of Trás-os-Montes and Alto Douro, Vila Real, Portugal, (in Portuguese). 181 p.

Correia, J. A. F. O.; De Jesus, A. M. P.; Silva, A. L. L.; Pedrosa, B.; Rebelo, C.; Calçada, R. 2017. FE simulation of S-N curves for a riveted connection using two-stage fatigue models, $A d$ vances in Computational Design, an International Journal 2: 333-348.

Cruz, A.; Simões, R.; Alves, R. 2012. Slip factor in slip resistant joints with high strength steel, Journal of Constructional Steel Research 70: 280-288. https://doi.org/10.1016/j.jcsr.2011.11.001

De Jesus, A. M. P.; Pinto, H.; Fernández-Canteli, A.; Castillo, E.; Correia, J. A. F. O. 2010. Fatigue assessment of a riveted shear splice based on a steel probabilistic model, International Journal of Fatigue 32(2): 453-462. https://doi.org/10.1016/j.ijfatigue.2009.09.004

EN 1090-2. 2011. Execution of steel structures and aluminium structures. Technical requirements for steel structures. European standard: European Committee for Standardization. Brussels

Gresnigt, A.; Sedlacek, G.; Paschen, M. 2012. Injection bolts to repair old bridges [online], [cited 22 August 2012], 349360. Available from Internet: http://www.epicuro.co.uk/ uploads/349.pdf

Kim, J.; Yoon, J.; Kang, B. 2006. Finite element analysis and modeling of structure with bolted joints, Applied Mathematical Modelling 31(5): 895-911. https://doi.org/10.1016/j.apm.2006.03.020

Kortiš, J. 2011. The numerical solution of the bolted connection with the low-quality injected bolts, in Proceedings of the 9th International Conference on new trends in statics and dynamics of buildings, 20-21 October 2011, Bratislava, Slovakia. $6 \mathrm{p}$.

Kwon, Y. D.; Goo, N. S.; Kim, S. Y.; Cho, M. H. 2002. Finite element modeling for static and dynamic analysis of structures with bolted joints, Trans. KSME A 26: 667-676.

Lazzarin, P.; Quaresimin, M. 1995. Analysis of fatigue behaviour of bolted joints in aluminium alloys. Department of Mechanical Engineering, University of Padova, Padova, Italy.

Maggi, Y. I.; Conclves, R. M.; Leon, R. T.; Ribeiro, L. F. L. 2005. Parametric analysis of steel bolted end plate connections using finite element modeling, Journal of Constructional Steel Research 6: 689-708. https://doi.org/10.1016/j.jcsr.2004.12.001 
Montgomery, J. 2008. Boundary condition influences on shank stress in 3D solid bolt simulation, in Conference proceedings 2008 Abaqus Users' Conference, May 19-22, Newport, Rhode Island, USA. $18 \mathrm{p}$.

SAS. 2011. "ANSYS". Version 12.0, Swanson Analysis Systems, Houston, TX.

Silva, J. 2009. Comparação Entre o Comportamento à Fadiga de Ligações Rebitadas e Aparafusadas: MSc. Thesis. University of Trás-os-Montes and Alto Douro, Vila Real, Portugal (in portuguese). $249 \mathrm{p}$.
Yorgun, C.; Dalcl, S.; Altay, G. A. 2004. Finite element modeling of bolted steel connections designed by double channel, Computers \& Structures 82: 2563-2571. https://doi.org/10.1016/j.compstruc.2004.04.003

Zhang, O.; Poirier, J. 2004. New analytical model of bolted joints, ASME Journal of Mechanical Design 126: 721-728. https://doi.org/10.1115/1.1760777

Mariana Ferreira RODRIGUES, born 1994 in São João da Madeira, Portugal, is Research Fellowship of Optics and Experimental Mechanics Laboratory (LOME) of INEGI/UP and CONSTRUCT/FEUP (Portugal). She obtained the MSc in Civil Engineering (structures) by Faculty of Engineering, University of Porto in 2017. Currently, her works in field of the Fatigue of old riveted steel bridges.

José CORREIA, born 1984 in Peso da Régua, Portugal, is Senior Researcher of Optics and Experimental Mechanics Laboratory (LOME) of INEGI/UP and CONSTRUCT/FEUP (Portugal). He is also Invited Professor at the structural mechanics section in the Civil Engineering Department of the University of Coimbra. He obtained the degrees BSc (2007) and MSc (2009) in Civil Engineering by the University of Trás-os-Montes e Alto Douro. He is specialist in steel and composite (steel and concrete) construction by the University of Coimbra in 2010. He is PhD in Civil Engineering by University of Porto in 2015. He is also co-author of more 30 papers in the most relevant scientific journals devoted to engineering materials and structures and 80 proceedings in international and national conferences, congresses and workshops. His is an expert in structural integrity, fatigue and fracture of materials and structures.

Bruno PEDROSA born 1993 in Leiria, Portugal, is a PhD candidate in Faculty of Science and Technology, University of Coimbra since September 2017. He is also a researcher at Institute for Sustainability and Innovation in Structural Engineering interested in innovative methods for strengthening operations of old steel and steel-concrete old bridges, namely concerning fatigue assessments. He obtained the MSc in Civil Engineering (Structural Mechanics) by Faculty of Science and Technology, University of Coimbra in 2017.

Abílio DE JESUS, born 1973 in Oliveira de Azeméis, Portugal, is an expert in Structural Integrity, Fatigue and Mechanical Testing. He obtained his Mechanical Engineering degree at Faculty of Engineering of the University of Porto (FEUP) in 1996, an MSc degree in 1999, and a PhD of University of Trás-os-Montes e Alto Douro in 2004. Currently he is a professor of the Department of Mechanical Engineering of FEUP. He is also co-author of more 100 papers in the most relevant scientific journals devoted to Engineering Materials and structures and more 200 proceedings in international and national Conferences, congresses and workshops. He has been a coordinator or researcher in several international (EU) and national projects (FCT and QREN).

Bruno CARVALHO born 1983 in Vila Real, Portugal, is Senior Engineer in Sibelco AS since 2016. He obtained the BSc and MSc in Civil Engineering (structures) by University of Trás-os-Montes and Alto Douro in 2006 and 2013, respectively. As a Civil Engineer he participated in many projects in Portugal, Brazil and Norway. His responsibilities include field execution supervising and budgets, business development as well as elaboration of proposals for clients, project management in areas such as mining industry, technical design positions in the oil \& gas industry and civil construction/ infrastructures.

Carlos REBELO obtained his PhD from The Technical University of Karlsruhe in 1992 and is currently Associate Professor in the Civil Engineering Department (DEC) of University of Coimbra, Portugal and researcher of the Institute for sustainability and Innovation in Structural Engineering, working in dynamics of structures, earthquake engineering, steel and mixed construction, bridges and support structures for wind energy converters.

José XAVIER graduated in Mechanical Engineering at University of Trás-os-Montes e Alto Douro (UTAD) in 1999. He completed a PhD degree at Arts et Métiers ParisTech in France in 2007, dealing with wood stiffness variability by coupling full-field measurements with the virtual fields method. After his $\mathrm{PhD}$, he held a position as research assistant at UTAD/CITAB (Ciência2008), during which he was responsible for the project: mechanical behaviour of bio-based materials and structures. Since February 2015, J. Xavier hold a position of guest lecturer (Prof. Auxiliar Convidado) at the Engineering Department of the School of Science and Technology (ECT) of UTAD.

Rui CALÇADA obtained the MSc in Civil Engineering Structures at Faculty of Engineering of the University of Porto (FEUP) in 1996 and the PhD in Civil Engineering at University of Porto in 2003. He is Full Professor at the Civil Engineering Department and Coordinator of the Centre of Competence in Railways of FEUP. He was principal investigator of 12 research projects and was member of the team of 10 research projects in the field of railways. His main research interests are: advanced models for traininfrastructure dynamic interaction; wayside (track, bridges, and transition zones) and on-board condition monitoring systems; advanced algorithms for RCM systems. He is member of the editorial board of the International Journal of Railway Technology. $\mathrm{He}$ is director of the $\mathrm{PhD}$ programme - iRail - Innovation in railway systems and technologies. 